\title{
O RISCO NA SOCIEDADE DE CONSUMO: SUPERENDIVIDAMENTO COMO PERDA DE CAPACIDADES
}

\section{EL RIESGO EN LA SOCIEDAD DE CONSUMO: SOBREEENDEUDAMIENTO DE LOS CONSUMIDORES COMO LA PÉRDIDA DE CAPACIDADES}

\author{
${ }^{1}$ Vagner Bruno Caparelli Carqui
}

\section{RESUMO}

O presente artigo visa analisar, de maneira crítica, os riscos que se verificam na sociedade de consumo, vinculando-se à ideia de modernidade líquida, desenvolvida por Zygmunt Bauman e tendo em vista o superendividamento do consumidor compreendido, nesse trabalho, como a perda de capacidades civis dos indivíduos. As necessidades surgidas na modernidade líquida estão relacionadas ao consumismo descartável, responsável, dentre outras situações, pela redefinição do significado do homem e do tempo. As atividades econômicas que promovem o consumismo indiscriminado fazem surgir na dinâmica dessa sociedade novos riscos. O artigo pretende demonstrar que um dos riscos da sociedade de consumo é, justamente, o superendividamento do consumidor. Para isso, faz uma ligação entre as teorias de Zygmunt Bauman (modernidade líquida), Ulrich Beck (sociedade de risco) e Amartya Sen (desenvolvimento como liberdade). A metodologia será realizada por meio de revisão bibliográfica, utilizando os métodos dedutivo e argumentativo.

Palavras-chave: Risco, Sociedade de consumo, Superendividamento

\section{RESUMEN}

Este artículo tiene como objetivo analizar, críticamente, los riesgos que existen en la sociedad de consumo, vinculándolo a la idea de la modernidad líquida, desarrollada por Zygmunt Bauman, considerando el sobreendeudamiento del consumidor entendido en este trabajo como la pérdida de capacidades civiles de los individuos. Las "necesidades" que surgen en la modernidad líquida están relacionados con el consumismo desechable, responsable, entre otras situaciones,por la redefinición del sentido del hombre y el tiempo. Las actividades económicas que promueven el consumismo indiscriminado dan lugar a nuevos riesgos en esta sociedad dinámica. El artículo sostiene que uno de los riesgos de la sociedad de consumo es, precisamente, el sobreendeudamiento de los consumidores. Para ello, establece un vínculo entre las teorías de Zygmunt Bauman (modernidad líquida), Ulrich Beck (sociedad del riesgo) y Amartya Sen (desarrollo y libertad). La metodología se llevará a cabo a través de revisión de la literatura, utilizando los métodos deductivos y argumentativos.

Palabras-claves: Riesgo, Sociedad de consumo, Sobreendeudamiento

\footnotetext{
${ }^{1}$ Mestrando em Direito Público pela Universidade Federal de Uberlândia - UFU, Minas Gerais (Brasil) Professor pela Universidade Presidente Antônio Carlos, UNIPAC, Minas Gerais (Brasil).

E-mail: brunocaparelli@uol.com.br
} 


\section{Introdução}

A modernidade líquida, difundida por Bauman, trouxe novos padrões às relações de consumo, a passagem de uma sociedade de consumo biológico - de subsistência básica - com características de durabilidade e necessidade, para uma sociedade pautada no consumismo descartável, gerou novos contornos às relações sociais.

Nesse cenário, o efeito do consumismo exacerbado extrapola a esfera privada e passa a ser um problema de interesse público, na medida em que os seus reflexos podem ser extremamente prejudiciais à vida do homo consumericus.

A sociedade de consumo, pautada pelo uso indiscriminado de crédito, onde a abundância e a opulência são características eminentes, faz surgir a necessidade de um estudo sobre o aumento significativo da oferta de crédito para o consumo que, embora promova o crescimento econômico, acarreta o fenômeno do superendividamento do consumidor.

O superendividamento já pode ser considerado uma patologia na sociedade massificada de consumo, pois, além de gerar uma grande exclusão social, acarreta a perda de condições mínimas de uma existência digna, criando um grande flagelo na sociedade.

O risco ligado a essa nova realidade, onde as relações de consumo tomam papel de protagonista na vida dos indivíduos deve abarcar, também, as situações de superendividamento do consumidor, dado que a volatilidade das relações e a falta de cálculo acerca dos problemas que o acesso ao crédito produz, geram grandes problemas sociais.

O superendividamento do consumidor, sob a ótica dos riscos na sociedade de consumo, pode ser compreendido, ainda, como a perda de capacidades civis dos indivíduos que se encontram nessa situação, tendo em vista que a impossibilidade de consumir, em um panorama que se movimento em função do consumo, faz com que o indivíduo seja reflexamente excluído da vida social.

\section{Modernidade líquida e os efeitos do consumismo exacerbado na sociedade}

A sociedade pós-moderna ${ }^{1}$, vinculando-se o trabalho à ideia de modernidade líquida desenvolvida por Bauman, trouxe uma nova configuração às estruturas comportamentais dos indivíduos.

\footnotetext{
${ }^{1} \mathrm{O}$ conceito pós-modernidade carrega uma tensão e, também, uma diversidade de entendimentos e críticas. Tema que gerou uma discussão acadêmica, dentro das ciências humanas, entre Habermas e Lyotard, ainda gera uma diversidade de correntes e opiniões. Lyotard, em "A condição pós-moderna", projetou a ideia de que a pós-modernidade estava ligada ao aparecimento de uma sociedade pós-
} 
Indispensável salientar que o presente artigo não pretende esgotar os posicionamentos existentes sobre o conceito de pós-modernidade, mesmo porque, tal debate ainda carece de um padrão que possa ser simplificado.

A dificuldade de estudar o assunto se dá justamente pela diversidade de posicionamentos e confusões que o controvertido conceito carrega. Tal dificuldade levou o sociólogo polonês, Zygmunt Bauman, a adotar outro conceito.

Uma das razões pelas quais passei a falar em "modernidade líquida" e não em "pós-modernidade" [...] é que fiquei cansado de tentar esclarecer uma confusão semântica que não distingue sociologia pós-moderna de sociologia da pós-modernidade, "pós-modernismo" de "pós-modernidade". No meu vocabulário, "pós-modernidade" significa uma sociedade (ou, se se prefere, um tipo de condição humana), enquanto "pós-modernismo" refere-se a uma visão de mundo que pode surgir, mas não necessariamente, da condição pósmoderna. Procurei sempre enfatizar que, do mesmo modo que ser um ornitólogo não significa ser um pássaro, ser um sociólogo da pós- modernidade não significa ser um pós-modernista, o que definitivamente não sou (Bauman, 2004, p. 321).

O cenário social que corresponde à modernidade líquida estabeleceu uma modificação significativa na identificação do homem e do tempo, de acordo com Bauman (2008, p.45), "podemos dizer que o consumismo líquido-moderno é notável, mais do que qualquer outra coisa, pela (até agora singular) renegociação do significado do tempo” (Bauman, 2008, p. 45).

Se antes o valor de alguém era auferido pelo que determinada pessoa representava na sociedade e, nessa lógica, ser alguém era importante. No decorrer histórico o ser humano passou a ter valor não pelo que era, mas por aquilo que detinha, nesse momento, o crédito obteve justificativa como um fim em si mesmo.

Se a sociedade impõe valores, e esses valores são alcançados pela posse de bens materiais, a única maneira de se conseguir um lugar cativo no status quo social é obtendo bens que, na maioria das vezes, não seria possível adquirir apenas com o rendimento básico.

industrial. Em sentido oposto, Habermas vinculou a ideia de que ainda não havia uma ruptura com a modernidade. Há posicionamentos no sentido de que estamos vivendo um período que pode ser chamado pós-moderno, entretanto, também há entendimentos de que ainda estamos presenciando a modernidade, embora com algumas modificações. Fredric Jameson deu pronfudidade ao tema ao enquadrar a pósmodernidade como um novo estágio na história, estágio que compreende um capitalismo que se vê diante de uma explosão tecnológica e se movimenta sem grandes barreiras frente a um Estado nacional enfraquecido. Sem prejuízo de qualquer uma das correntes. O trabalho vincula- se a ideia de modernidade líquida, desenvolvida por Bauman, por entender que tal teoria se enquadra nas situações que permeiam a sociedade de consumo na atualidade. 
Essa mudança de concepções, em mais uma transição, agora concebe o homem com aquilo que ele aparenta ser, desse fato, não parece difícil entender porque vivenciamos a era do hiperconsumo e da sociedade de aparências, que geram grandes problemas sociais e econômicos como o superendividamento.

\begin{abstract}
A economia consumista se alimenta do movimento das mercadorias e é considerada em alta quando o dinheiro mais muda de mãos; e sempre que isso acontece, alguns produtos de consumo estão viajando para o depósito de lixo. Numa sociedade de consumidores, de maneira correspondente, a busca da felicidade - o propósito mais invocado e usado como isca nas campanhas de marketing destinadas a reforçar a disposição de consumidores para se separarem de seu dinheiro (ganhou ou que se espera ganhar) - tende a ser redirecionada do fazer coisas ou de sua apropriação (sem mencionar seu armazenamento) para a sua remoção - exatamente do que se precisa para fazer crescer o PIB. Para a economia consumista, o foco anterior, hoje quase abandonado, prenuncia a pior das preocupações: a estagnação, suspensão ou desgaste do ardor de comprar. O segundo foco, contudo, traz um bom prognóstico: outra rodada de compras. A menos que complementado pelo impulso de se desfazer e se descartar, o impulso da mera aquisição e posso armazenaria problemas para o futuro (Bauman, 2008, p. 51).
\end{abstract}

O conceito mais essencial de superendividamento pode ser compreendido como "a impossibilidade global de o devedor pessoa física, consumidor, leigo e de boa-fé, pagar todas as suas dívidas atuais e futuras de consumo (excluídas as dívidas com o fisco, oriundas de delitos e alimentos)" (Marques apud Neto, 2009, p. 14).

Nesse sentido, o superendividamento das pessoas físicas de boa-fé, caracterizado pela impossibilidade manifesta pelo devedor de boa-fé de honrar com suas dívidas não profissionais, é um tema de elevada importância jurídica e social, visto que, pode ser responsável pelo flagelo da exclusão social e acarretar a perda de condições mínimas para uma existência digna.

Evidentemente que tal conceito não esgota as possibilidades de compreensão do fenômeno do superendividamento do consumidor que, na modernidade líquida, pode ser compreendido como a perda de capacidades civis e, consequentemente, da liberdade dos indivíduos que se encontram diante desse novo risco da sociedade para o consumo.

As atividades econômicas do mundo líquido moderno se mostram cada vez mais distantes de uma ética solidária, de uma preocupação para com o outro, de um senso de civilidade que engloba a análise e os riscos de atividades financeiras agressivas e desmedidas.

A possibilidade de povoar o mundo com pessoas mais carinhosas e a induzilas a dar mais carinho não figura nos panoramas pintados na utopia consumista. As utopias privatizadas dos caubóis e vaqueiras da era 
consumista demonstram, em vez disso, um expandido "espaço livre" (livre para mim mesmo, claro), uma espécie de espaço vazio do qual o consumidor líquido moderno, inclinado a apresentações solo, e apenas a elas, nunca tem o suficiente. O espaço de que os consumidores líquidos modernos necessitam e pelo qual ouvem recomendações de todos os lados para lutar só pode ser conquistado pela expulsão de outros seres humanos - em particular os tipos de homem que se importam com os outros ou podem precisar que alguém se importe com eles (Bauman, 2011, p. 60).

A passagem de uma sociedade de consumo básico e de subsistência para uma sociedade consumista - de consumo descartável - é uma das grandes modificações consolidadas pela modernidade líquida ${ }^{2}$.

Bauman afirma que "de maneira distinta do consumo, que é basicamente uma característica e uma ocupação dos seres humanos como indivíduos, o consumismo é um atributo da sociedade" (2008, p. 41).

O consumo, compreendido como uma atividade indispensável à subsistência biológica "tem raízes tão antigas quanto os seres vivos - e com toda certeza é parte permanente e integral de todas as formas de vida conhecidas a partir de narrativas históricas e relatos etnográficos" (Bauman, 2008, p.37).

A nova configuração econômica de sociedade fluída tem como alicerce o consumismo que, diferentemente do consumo, se caracteriza pela aquisição de tudo aquilo que possa proporcionar a felicidade e o alívio instantâneo.

Pode-se dizer que o "consumismo" é um tipo de arranjo social resultante da reciclagem de vontades, desejos e anseios humanos rotineiros, permanentes e, por assim dizer, "neutros quanto ao regime", transformando-os na principal força propulsora e operativa da sociedade, uma força que coordena a reprodução sistêmica, a integração e a estratificação sociais, além da formação de indivíduos humanos, desempenhando ao mesmo tempo um papel importante nos processos de auto-identificação individual e de grupo, assim como na seleção e execução de políticas de vida individuais (Bauman, 2008, p. 41).

\footnotetext{
${ }^{2}$ Tudo isso fazia sentido na sociedade sólido-moderna de produtores - uma sociedade, permitam-me repetir, que apostava na prudência e na circunspecção a longo prazo, na durabilidade e na segurança, e sobretudo na segurança durável de longo prazo. Mas o desejo humano de segurança e os sonhos de um "Estado estável" definitivo não se ajustam a uma sociedade de consumidores. No caminho que conduz a esta, o desejo humano de estabilidade deve se transformar, e de fato de se transforma, de principal ativo do sistema em seu maior risco, quem sabe até potencialmente fatal, uma causa de disrupção ou mau funcionamento, Dificilmente poderia ser de outro jeito, já que o consumismo, em aguda oposição às formas de vida precedentes, associa a felicidade não tanto à satisfação de necessidades (como suas versões oficias tendem a deixar explícito), mas a um volume e uma intensidade de desejos sempre crescentes, o que por sua vez implica o uso imediato e a rápida substituição dos objetos destinados a satisfazê-la (Bauman, 2008, p. 44).
} 
A principal transformação erguida pela passagem da sociedade sólido-moderna para a modernidade líquida, se dá pela transferência do consumo durável para o consumo descartável, ou seja, pela prática ininterrupta do ato de consumir, principal finalidade dos indivíduos dessa sociedade.

Diante dessa realidade, o homo consumericus encontra a sua mais alta potência de ação, viver para consumir passa a ser a regra - e não mais uma patologia - da vida em sociedade.

As novas facetas do consumismo esbarram nos conceitos éticos, mas não são intimidadas por padrões de responsabilidade e consciência cívica. O crédito, compreendido como o veículo condutor para o consumismo, tem no marketing um importante aliado para a popularização e divulgação de seu conceito.

A democratização do crédito se deu através de uma releitura histórica desse instituto, o conceito inicial de que o crédito era sinônimo de poucas condições financeiras, entendido como referência à pobreza ou à prodigalidade foi substituído pela possibilidade de melhorar o acesso a bens e serviços, contribuindo para o aumento da qualidade de vida das famílias.

Os EUA foram pioneiros nesta transformação conceitual, estabelecendo o crédito como um importante mecanismo na busca pela dinamização da economia nacional ${ }^{3}$.

A oferta e a publicidade, unidas, são responsáveis pela realização da "felicidade" instantânea decorrente da prática de consumo constante. O grande problema, contudo, é que a publicidade vende o crédito, e não o dinheiro, como muitas propagandas fazem pensar.

A partir do século XXI, a sociedade brasileira também presenciou a grande expansão e o desenvolvimento "democrático" do fenômeno da concessão de crédito. Primeiramente, tal acontecimento consubstanciou-se em um interesse econômico advindo do crescimento da produção industrial que necessitava de um mercado de consumo mais amplo no país. Em

\footnotetext{
${ }^{3}$ Nos Estados Unidos, o papel do cartão de crédito no contexto do superendividamento ou da falência dos consumidores vem sendo alvo de importante debate num ambiente em que altos níveis de débito são encorajados pela política econômica e também pelas instituições financeiras. Alguns apontam o cartão de crédito como uma forma de crédito perigosa porque incentiva os consumidores a realizar gastos incompatíveis com a renda, gerando situações de endividamento excessivo. No maior estudo feito nos EUA por Teresa A. Sullivan, Elisabeth Warren e Jay Lawrence Westbrook, o cartão de crédito representa uma parte substancial das dívidas acumuladas nos processos de falência. Levantamento realizado em Ohio pela juíza Barbara Sellers em 1997 apontou que 83\% dos devedores que pediram falência tinham algum tipo de cartão de crédito. No mesmo ano, o juiz Randall Newsome calculou que 95\% dos devedores que pediram falência na Califórnia tinham dívidas com cartão de crédito arroladas no seu passivo (Lima, 2012, p. 243).
} 
seguida, o interesse do mercado financeiro em garantir ampla circulação de crédito ocasionou a massificação desordenada do acesso ao crédito.

\begin{abstract}
Embora seja inegável que o acesso ao crédito constitui ferramenta indispensável para o desenvolvimento das economias modernas, a grande complexidade dessas novas formas de contratação, que envolvem um conjunto intrincado de riscos, custos e responsabilidades, acaba por prejudicar a compreensão do consumidor a respeito dos termos e condições do negócio e, consequentemente, dificultar sua avaliação sobre a adequação do contrato a suas necessidades, interesses e, acima de tudo, possibilidades econômicas. Assim, essa assimetria generalizada de informações e conhecimentos potencializa a vulnerabilidade do consumidor, pois, a mais de permitir a formação de falsas expectativas sobre os produtos e serviços adquiridos, pode conduzi-lo a escolhas impróprias e de consequências perversas - e não apenas no que tange a seu patrimônio, mas também a sua qualidade de vida, dignidade, saúde e segurança (Marques, 2010, p. 07).
\end{abstract}

Os principais problemas ocasionados pelo crédito ao consumo no país estão relacionados com as altas taxas de juros praticas no mercado financeiro nacional, o elevado custo do dinheiro, as insuficientes informações sobre os riscos do crédito ao consumidor (falta de clareza), as cláusulas abusivas presentes nos contratos e, infelizmente, pela grande quantidade de publicidade enganosa que impera em nosso país.

O quadrante de consumo em larga escala, combinado com uma modalidade de contrato que não permita a compreensão dos consumidores, i.e., sem orientação adequada (e, por isso, desconhecendo os juros, os custos e os efeitos do inadimplemento), somados ao desequilíbrio conjuntural do desemprego, por exemplo (ou da desaceleração da economia, variação cambial, dentre outros fatores), são fatores que provocam a incapacidade dos consumidores fazerem frente a suas obrigações pecuniárias oriundas de empréstimos que acabam por se tornarem malsucedidos (Bessa, 2008, p.

152).

Outro fator observado é o fenômeno da "bancarização", envolvimento cada vez maior e mais frequente do consumidor com os serviços bancários, ocasionado pela popularização e massificação do uso do cartão de crédito, do cheque especial e, por fim, do empréstimo consignado em folha de pagamento.

A ética contemporânea da felicidade não é só consumista, mas essencialmente ativista, construtivista. Bem entendido, não é mais um controle modelar das próprias paixões, mas o de otimizar as potencialidades; não mais a aceitação resignada do desgaste dos anos, e sim a eterna juventude do corpo; não mais a sabedoria, e sim uma eficiente atividade competitiva de si sobre si mesmo; não mais a inteira concordância de si para consigo mesmo, mas a diversidade high-tech, correlata às exigências de 
proteção, de entretenimento, de auto-rendimento do capital corpo (Lipovetsky, 2005, p. 34)

É inegável que o acesso ao crédito potencializou a economia do país e, além disso, possibilitou às classes econômicas de menor poder aquisitivo uma vida mais digna.

Contudo, o interesse estritamente financeiro da concessão creditícia e a inobservância de preceitos éticos básicos para a abertura e oferecimento do crédito à população, aliados ao marketing que coloca a felicidade como objeto de consumo, ocasionaram o superendividamento da população.

Do exposto, o superendividamento das pessoas físicas de boa-fé, caracterizado pela impossibilidade manifesta pelo devedor de boa-fé de honrar com suas dívidas não profissionais, é um tema de elevada importância jurídica e social, visto que, leva à diminuição das capacidades civis dos consumidores.

A perda da capacidade de consumir em um panorama que se movimenta pelo consumo, como já demonstrado, faz com que o indivíduo superendividado seja considerado “inadequado" pelo sistema e, portanto, reflexamente excluído da sociedade.

\section{O superendividamento do consumidor: novo risco da sociedade de consumo}

O superendividamento dos consumidores pode ser visto, também, como um risco possível da sociedade que se movimenta para o consumo (consumismo), principalmente pela volatilidade das relações e pela falta de cálculo acerca dos problemas que o acesso ao crédito, sem uma análise apurada dos riscos que envolvem, pode causar.

A sociedade de risco, foco dos estudos de Ulrich Beck, engloba, também, os riscos relacionados ao consumo desenfreado, ao crédito facilitado e à dinâmica de fortalecimento do mercado financeiro.

En La modernidad avanzada, la producción social de riqueza va acompanãda sistemáticamente por la producción social de riesgos. Por tanto, los problemas y conflictos de reparto de la sociedad de la carência son sustituidos por los problemas y conflictos que surgen de la producción, definición y reparto de los riesgos producidos de manera científico-técnica. Este cambio de la lógica del reparto de la riqueza em la sociedad de la carência a la lógica de reparto de los riesgos em la modernidad desarrollada está vinculado históricamente a (al menos) dos condiciones. Em primer lugar, este cambio se consuma (como sabemos hoy) allí donde y en la medida em que mediante el nível alcanzado por las fuerzas productivas 
humanas y tecnológicas y por las seguridades y regulaciones del Estado social se puede reducir objetivamente y excluir socialmente la miséria material aunténtica. En segundo lugar, este cambio categorial depende ao mismo tiempo de que al hilo de crecimiento exponencial de las fuerzas productivas en el processo de modernización se liberen los riesgos y los potenciales de autoamenaza em uma medida desconocida hasta el momento (Beck, 2008, p.25)

Como apontado por Beck, o crescimento da produção técnico-científica, aliada ao consumo em larga escala e sem controle, faz surgir riscos na sociedade de consumidores.

Um dos riscos possíveis da sociedade de crédito facilitado, onde o mercado financeiro depende da movimentação da economia, principalmente através do consumo, é a situação de superendividamento do consumidor.

O conceito de sociedade de risco está inserido em uma situação que Beck denomina "modernização reflexiva" que, de acordo com o autor, "significa autoconfrontação com os efeitos da sociedade de risco que não podem ser tratados e assimilados no sistema da sociedade industrial” (Beck, 2008, p. 16).

Se, no fundo, a modernização simples (ou ortodoxa) significa primeiro a desincorporação e, segundo, a reincorporação das formas sociais tradicionais pelas formas sociais industriais, então a modernização reflexiva significa primeiro a desincorporação e, segundo, a reincorporação das formas sociais industriais por outra modernidade. Assim, em virtude do seu inerente dinamismo, a sociedade moderna está acabando com suas formações de classe, camadas sociais, ocupação, papéis dos sexos, família nuclear agricultura, setores empresariais e, é claro, também com os pré-requisitos e as formas contínuas do progresso técnico-econômico. Este novo estágio, em que o progresso pode se transformar em autodestruição, em que um tipo de modernização destrói outro e o modifica, é o que eu chamo de etapa da modernização reflexiva. (Beck, 2008, p. 12).

A facilitação do acesso ao crédito traz riscos reais aos consumidores e a economia, o padrão de consumo demasiado faz com que a situações de superendividamento sejam potencializadas a uma situação crônica difícil de ser controlada.

Embora seja inegável que o acesso ao crédito constitui ferramenta indispensável para o desenvolvimento das economias modernas, a grande complexidade dessas novas formas de contratação, que envolvem um conjunto intrincado de riscos, custos e responsabilidades, acaba por prejudicar a compreensão do consumidor a respeito dos termos e condições do negócio e, consequentemente, dificultar sua avaliação sobre a adequação do contrato a suas necessidades, interesses e, acima de tudo, possibilidades econômicas. Assim, essa assimetria generalizada de informações e conhecimentos potencializa a vulnerabilidade do consumidor, pois, a mais de 
permitir a formação de falsas expectativas sobre os produtos e serviços adquiridos, pode conduzi-lo a escolhas impróprias e de consequências perversas - e não apenas no que tange a seu patrimônio, mas também a sua qualidade de vida, dignidade, saúde e segurança (Marques, 2010, p. 7)

O indivíduo superendividado, quando em situações extremas, perde a sua capacidade de consumo e, além disso, vê a sua dignidade diminuída frente a impotência de conseguir gerir seus gastos e suas necessidades, mesmo que básicas.

Encarar o superendividamento do consumidor como um risco decorrente da "modernidade reflexiva" tem como objetivo a regulação das possíveis consequências desse efeito no que toca a vida dos indivíduos inseridos nessa dinâmica consumista.

\section{Boa-fé como norteadora das relações de consumo}

O desenvolvimento acentuado do capitalismo, durante os séculos XIX e XX, evidenciou os abusos praticados pelos agentes econômicos em face dos mais vulneráveis, diante disso, surgiu a necessidade de se implementar uma legislação específica para o tratamento das relações de consumo que se massificaram na época.

Com a finalidade de coibir os abusos praticados pelos organismos econômicos e proteger a classe consumidora, institui-se, em 1990, o Código de Defesa do Consumidor.

Desde então, surgiu a primeira acepção moderna de boa-fé objetiva no direito brasileiro, o artigo $4^{\circ}$ estabeleceu que as políticas nacionais de relações de consumo deveriam ser fundadas sempre com base na boa-fé e equilíbrio nas relações entre os consumidores e fornecedores.

A boa-fé auxilia sobremaneira a aplicação do princípio da justiça contratual, contudo numa ótica mais formal que substancial, porquanto através dela se tem a filtragem de comportamentos mediante funções específicas, além de sua característica própria, voltada à legitimidade da obrigação como processo. Ponha-se que essa assertiva não seja unânime, considerando parte da doutrina que compreende a boa-fé apenas como um "pseudocritério" ou uma "entorse científica" no relacionamento com a justiça contratual. A boa- fé detém três funções básicas e autônomas no direito privado: (i) princípio jurídico de interpretação dos contratos; (ii) caracterizador de deveres de conduta; e (iii) indicativa de limites para o exercício de direitos subjetivos (Martins, 2009, p. 341). 
A partir da constituição do Código de Defesa do Consumidor, o conceito de boa-fé deixou de ser utilizado em sua caracterização subjetiva, como um estado de consciência do indivíduo, e passou a exigir comportamentos objetivamente adequados aos conceitos de colaboração para alcançar os fins de uma relação obrigacional, a lealdade e a honestidade.

\begin{abstract}
A concepção da obrigação como um processo e como uma totalidade concreta põe em causa o paradigma tradicional do direito das obrigações, fundado na valorização jurídica da vontade humana, e inaugura um novo paradigma para o direito obrigacional, não mais baseado exclusivamente no dogma da vontade (individual, privada ou legislativa), mas na boa-fé objetiva. No vínculo obrigacional considerado como uma totalidade, como um complexo de direitos (direitos de crédito, direitos formativos), deveres (principais e secundários, laterais e instrumentais), sujeições, pretensões, obrigações, exceções, ônus jurídicos, legítimas expectativas etc., visualizase, como já referi, além do aspecto externo, o aspecto interno, vale dizer, aquele conjunto inseparável de elementos que coexiste, material e complessivamente, no vínculo que liga credor e devedor, aí inclusos os elementos consistentes às suas fontes e aos seus limites (Costa, 1999, p.
\end{abstract} 394).

A boa-fé objetiva, no que tange ao fenômeno do superendividamento, traz a importância de se estabelecerem valores como o dever de assistência, de cooperação e de colaboração mútua entre os contratantes com a finalidade de diminuir os efeitos negativos do endividamento excessivo em relação aos consumidores.

O que em verdade se passa é que todos os homens têm de portar-se com honestidade e lealdade, conforme o uso do tráfego, pois daí resultam relações jurídicas de confiança, e não só relações morais. O contrato não se elabora a súbitas, de modo que só importe a conclusão, e a conclusão mesma supõe que cada figurante conheça o que se vai receber ou o que vai dar. Quem se dirige a outrem, ou invita outrem a oferecer, ou expõe ao público, capta a confiança indispensável aos tratos preliminares à conclusão do contrato (Miranda, 1999, p. 507).

No cenário atual, a boa-fé objetiva figura como um importante mecanismo na busca pelo princípio nacional de luta contra as exclusões sociais, já que quando este princípio é concretizado na forma teórica e prática do contrato, garante maior segurança aos consumidores frente ao endividamento muito oneroso.

O direito brasileiro impõe normas de conduta pela ordem constitucional de solidariedade e proteção. A Constituição Federal compreende que a boa-fé é uma cláusula geral que deve estar em harmonia com os princípios gerais do ordenamento como liberdade, 
solidariedade e justiça, ou seja, a boa-fé deve estar em concordância com os princípios que gerenciam o ordenamento jurídico nacional para que tenha força normativa suficiente para fazer valer seus deveres anexos no sistema global.

\section{$5 \quad$ Superendividamento como perda de capacidades}

A lógica do mercado de consumo da sociedade fluída está presa, ideologicamente, a um desenvolvimento sem liberdade ${ }^{4}$. O que se percebe, através da análise econômica do direito, é que a "evolução" da economia vem acompanhada de uma perda das liberdades individuais em detrimento dos interesses especulativos e financeiros dos grandes operadores do crédito.

Essa contradição não condiz com uma perspectiva saudável, do ponto de vista social, para que a economia se desenvolva sem agressão aos direitos fundamentais dos indivíduos.

Nesse panorama, a solidariedade não figura como um padrão cotidiano nas atividades econômicas e de consumo. A ética parece ter suplantado à força dos interesses pessoais e financeiros, sendo desvinculada dos padrões de consumo.

[...] não se pode falar de responsabilidade se a noção de sujeito é ilusória e se a possibilidade de autonomia do espírito é inconcebível. A consciência da responsabilidade é característica de um indivíduo-sujeito dotado de autonomia (dependente como toda autonomia). A responsabilidade contudo necessita ser irrigada pelo sentimento de solidariedade, ou seja, de pertencimento a uma comunidade. Devemos assumir simultaneamente a responsabilidade por nossa vida (não deixar que forças ou mecanismos anônimos dirijam o nosso destino) e em relação aos outros (Morin, 2007, p.100).

\footnotetext{
${ }^{4}$ Sen (2010, p. 9) nos remete ao seguinte pensamento: vivemos em um mundo de opulência sem precedentes, de um tipo que teria sido difícil até mesmo imaginar um ou dois séculos atrás. Também tem havido mudanças notáveis para além da esfera econômica. O século XX estabeleceu o regime democrático e participativo como o modelo preeminente de organização política. Os conceitos de direitos humanos e liberdade política hoje são parte da retórica prevalecente. As pessoas vivem em média muito mais tempo do que no passado. Além disso, as diferentes regiões do globo estão agora mais estreitamente ligadas do que jamais estiveram, não só nos campos da troca, do comércio e das comunicações, mas também quanto a ideias e ideais interativos. Entretanto, vivemos igualmente em um mundo de privação, destruição e opressão extraordinárias. Existem problemas novos convivendo com antigos - a persistência da pobreza e de necessidades essenciais não satisfeitas, fomes coletivas e fome crônica muito disseminadas, violação de liberdades políticas elementares e de liberdades formais básicas, ampla negligência diante dos interesses e da condição de agente das mulheres e ameaças cada vez mais graves ao nosso meio ambiente e à sustentabilidade de nossa vida econômica e social. Muitas dessas privações podem ser encontradas, sob uma forma ou outra forma, tanto em países ricos como em países pobres. Superar esses problemas é uma parte central do processo de desenvolvimento.
} 
A solidariedade para com o outro não mais é exercida pela sociedade de consumidores, cada vez mais individualizada e dissociada de uma noção de comunidade.

O desenvolvimento da economia, além de demonstrar-se cada vez mais ligado à perda de liberdades individuais, está carente de uma ética de responsabilidade e de solidariedade para com o outro.

O liberalismo econômico, justificando sua atividade na igualdade - apenas formal dos indivíduos, faz valer, sob as expensas dos consumidores, a maximização do lucro e das atividades financeiras, sem uma preocupação suficiente quanto aos riscos que essa atividade financeira desregulada pode ocasionar.

Mas, como a igualdade a que se arrima o liberalismo é apenas formal, e encobre, na realidade, sob seu manto de abstração, um mundo de desigualdades de fato - econômicas, sociais, políticas e pessoais -, termina "a apregoada liberdade, como Bismarck já o notara, numa real liberdade de oprimir os fracos, restando a estes, afinal das contas, tão-somente a liberdade de morrer de fome (Bonavides, 1996, p. 61).

Um desenvolvimento econômico que, também, se pretende emancipatório no que tange as liberdades dos indivíduos, não deve reduzir a pobreza à comparação de renda, essa lógica defendida por alguns economistas não mais se coaduna com as necessidades pósmodernas.

\begin{abstract}
De acordo com Sen (2010, p.120), uma renda inadequada é, com efeito, uma forte condição predisponente de uma vida pobre. Já que isso é aceito, então por que tanta preocupação com ver a pobreza de perspectiva da capacidade (em vez de pela clássica avaliação da pobreza com base na renda)? Os argumentos em favor da abordagem da pobreza como privação de capacidades são, a meu ver, os seguintes: 1) A pobreza pode sensatamente ser identificada em termos de privação de capacidades; a abordagem concentra-se em privações que são intrinsecamente importantes (em contraste com a renda baixa, que é importante apenas instrumentalmente). 2) Existem outras influências sobre a privação de capacidade - e, portanto, sobre a pobreza real - além do baixo nível de renda (a renda não é o único instrumento de geração de capacidades). 3) A relação instrumental entre baixa renda e baixa capacidade é variável entre comunidades e até mesmo entre famílias e indivíduos (o impacto da renda sobre as capacidades é contingente e condicional).
\end{abstract}

Em consonância com o pensamento do economista acima citado, a pobreza não pode ser considerada única e exclusivamente do ponto de vista de renda dos indivíduos ${ }^{5}$, mas sim

\footnotetext{
${ }^{5}$ A ideia de que pobreza é simplesmente escassez de renda está razoavelmente estabelecida na literatura sobre o tema. Não é uma ideia tola, pois a renda - apropriadamente definida - tem enorme
} 
da relação com a perda de capacidades civis e, em consequência, com a perda da liberdade desses indivíduos.

Esse enfoque reiterado se revela pela importância que a liberdade individual tem no âmbito da sociedade líquido-moderna, uma vez que a "[...] razão para considerar tão crucial a liberdade substantiva é que a liberdade é não apenas a base da avaliação de êxito e fracasso, mas também um determinante principal da iniciativa individual e da eficácia social" (Sen, 2010, p. 33).

O superendividamento é justamente a perda ou diminuição acentuada das capacidades do consumidor. A perda da capacidade de consumir em um panorama que se movimenta pelo consumo faz com que o indivíduo superendividado seja considerado "inadequado" pelo sistema e, portanto, reflexamente excluído da sociedade.

Sen afirma que houve o "empobrecimento da economia do bem-estar como consequência do crescente distanciamento entre ética e economia e particularmente da inadequação dos critérios avaliatórios empregados em economia, em especial na moderna economia do bem-estar" (Sen, 1999, p. 67).

Esse distanciamento entre ética e economia e a não regulação pelo direito faz com que as modernas atividades de consumo figurem como principal causa do superendividamento da população, fenômeno cada vez mais constante e prejudicial aos consumidores.

A sensação de invulnerabilidade à ética que parece permear a economia preditiva surge em parte da alegada força da hipótese de que 0 comportamento humano, pelo menos em questões econômicas, pode ser satisfatoriamente previsto com base na maximização do auto-interesse (Sen, 1999, p. 68).

A ideologia consumista pautada pelo individualismo figura como força potencial do aumento das situações de risco para o consumidor, principalmente nas operações de crédito. O interesse das instituições financeiras em elevar seus lucros está acompanhado de um vazio legislativo que torna a regulação dessas operações cada vez mais difícil.

influência sobre o que podemos ou não podemos fazer. [...] Entretanto, existe um argumento igualmente bom para não terminar apenas com a análise da renda. A clássica análise de John Rawls sobre os "bens primários" fornece um quadro mais amplo dos recursos de que as pessoas necessitam independentemente de quais sejam seus respectivos objetivos; nele inclui-se a renda, mas também outros "meios" de uso geral. Os bens primários são meios de uso geral que ajudam qualquer pessoa a promover seus próprios fins, como "direitos, liberdades e oportunidades, renda e riqueza e as bases sociais do respeito próprio". A concetração em bens primários na estrutra rawlsiana relaciona-se a essa visão de vantagem individual segundo as oportunidades que os indivíduos tem para buscar seus objetivos (Sen, 2010, p. 101). 
A honra obriga-nos a assumir os nossos pensamentos e não aqueles ditos por ordem ou por conformidade. Impõe o respeito ("honrar") por nossa assinatura e por nossa palavra. Exige que sejamos, em nossas ações, dignos da imagem que desejamos ter de nós mesmos; o termo "dignidade" humana ganha sentido quando significa que sabemos obedecer à nossa honra e respeitar a dos demais. Lealdade e honestidade são qualidades simultaneamente para si (honra) e para os outros. A ética para si, no sentido em que comporta lealdade, honra e responsabilidade, conduz à ética para outro (Morin, 2007, p. 99).

A falta de ética empregada por essas empresas, dentro de uma perspectiva cada vez mais distante da preocupação da economia com os problemas sociais, gera aos consumidores situações de superendividamento acentuado e, portanto, de difícil reparação.

O endividamento excessivo não pode ser considerado apenas da aferição de renda dos indivíduos, mas sim da consideração e análise de perda das capacidades ${ }^{6}$, vez que, como assinala Amartya Sen, “a privação relativa de rendas pode resultar em privação absoluta de capacidades" (2010, p. 122).

Superendividar-se é, nesse contexto, além da diminuição de renda, uma forma de ser privado de capacidades civis que são indispensáveis a uma vida com o mínimo de dignidade e inclusão social.

A "capacidade" [capability] de uma pessoa consiste nas combinações alternativas de funcionamentos cuja realização é factível para ela. Portanto, a capacidade é um tipo de liberdade: a liberdade substantiva de realizar combinações alternativas de funcionamentos (ou, menos formalmente expresso, a liberdade para ter estilos de vida diversos) (Sen, 2010, p. 105).

Garantir que as capacidades civis do superendividado sejam mantidas nessas situações é de extrema importância, vez que o indivíduo que tem suas condições mínimas de vida não asseguradas dificilmente conseguirá se reestabelecer no mercado de consumo.

\footnotetext{
${ }^{6}$ O que a perspectiva da capacidade faz na análise da pobreza é melhorar o entendimento da natureza e das causas da pobreza e privação desviando a atenção principal dos meios (e de um meio específico que geralmente recebe atenção exclusiva, ou seja, a renda) para os fins que as pessoas tem razão para buscar e, correspondentemente, para as liberdades de poder alcançar esse fins. Os exemplos apresentados brevemente aqui ilustram o discernimento adicional resultante dessa extensão básica. As privações são vistas em um nível mais fundamental - mais próximo das demandas informacionais da justiça social. Daí a relevância de perspectiva da pobreza baseada na capacidade (Sen, 2010, p. 123).
} 


\section{Conclusão}

As mudanças nos padrões de consumo, o risco da atividade financeira que se projeta com base no consumismo em larga escala e as novas demandas que o "padrão" social estabelece, são circunstâncias que potencializam as situações de superendividamento do consumidor.

À luz dessas perspectivas, a análise das consequências do superendividamento é de extrema importância e relevância social, na medida em que seus efeitos geram reflexos em toda a sociedade.

A modernidade líquida promoveu uma mudança significativa na identificação e nos valores dos homens, além de ter modificado, também, o significado de tempo, tais mudanças repercutiram na passagem de uma sociedade cujo consumo se pautava nas necessidades básicas e de longa duração para uma sociedade com um apego ao consumismo descartável, onde a noção de durabilidade e preocupação com o futuro já não figuram mais nas prioridades dos indivíduos.

A movimentação da economia, na modernidade líquida, se apresenta cada vez mais distante de uma ética solidária, sem qualquer preocupação com a dignidade do outro. A atividade econômica estabelecida para uma finalidade - a ampliação e ininterrupção do mercado de consumo - não engloba os riscos que essa estratégia carrega.

A concepção de crédito como dinheiro, trazida e disseminada pelo marketing financeiro que atua sem a regulação necessária no país, fez surgir uma sociedade de consumo que se movimenta pelo acumulo desproporcional de dívidas futuras que fogem do controle orçamentário da maioria das famílias.

O superendividamento, nesse sentido, deve ser entendido como a perda de capacidades civis dos consumidores pessoas físicas de boa-fé, diante da diminuição abrupta de renda, ocasionada pelo endividamento excessivo.

\section{$7 \quad$ Referências}

BAUMAN, Zygmunt. A ética é possível num mundo de consumidores? Rio de Janeiro: Zahar, 2011.

BAUMAN, Zygmunt. Entrevista com Zygmunt Bauman. Tempo Social, v. 16, n. 1 São Paulo, junho de 2004. Entrevista concedida a Maria Lúcia Garcia Pallares-Burke. Disponível em: http://www.scielo.br/pdf/ts/v16n1/v16n1a15.pdf. Acesso em: 12/08/2014. 
BAUMAN, Zygmunt. Vida para o consumo: a transformação das pessoas em mercadoria. Rio de Janeiro: Zahar, 2008.

BECK, Ulrich. La sociedad del riesgo. Barcelona: Paidós, 2008.

BECK, Ulrich; GIDDENS, Anthony; LASH, Scott. Modernização reflexiva. São Paulo: Editora da Universidade Estadual Paulista, 1997.

BESSA, Leonardo Roscoe; MOURA, Walter José Faiad De. Impressões atuais sobre o superendividamento: sobre a $7^{\text {a }}$ conferência internacional de serviços financeiros e reflexões para a situação brasileira. Revista de Direito do Consumidor, São Paulo, n. 65, jan./mar. 2008.

BONAVIDES, Paulo. Do estado liberal ao estado social. São Paulo: Malheiros, 1996.

COSTA, Judith Martins. A boa-fé no direito privado: sistema e tópica no processo obrigacional. São Paulo: Editora Revista dos Tribunais, 1999.

LIMA, Clarissa Costa De. O cartão de crédito e o risco de superendividamento: uma análise da recente regulamentação da indústria de cartão de crédito no Brasil e nos Estados Unidos. Revista de Direito do Consumidor, n. 81, São Paulo: Revista dos Tribunais, janeiro-março, 2012.

LYPOVETSKY, Gilles. A sociedade pós-moralista: o crepúsculo do dever e a ética indolor dos novos tempos. Barueri: Manole, 2005.

MARQUES, Cláudia Lima; LIMA, Clarissa Costa; BERTONCELLO, Karen Rick Danilevicz. Prevenção e tratamento do superendividamento: caderno de investigações científicas. Brasília: DPDC/SDE, 2010.

MARTINS, Fernando Rodrigues. Princípio da justiça contratual. Coleção Prof. Agostinho Alvim. São Paulo: Saraiva, 2009.

MORIN, Edgar. O método 6: ética. Porto Alegre: Sulina, 2007.

NETO, André Perin Schmidt. Superendividamento do consumidor: conceito, pressupostos e classificação. Revista de Direito do Consumidor, n.71, São Paulo: Revista dos Tribunais, julho-setembro, 2009.

SEN, Amartya. Sobre ética e economia. São Paulo: Companhia das Letras, 1999.

SEN, Amartya. Desenvolvimento como liberdade. São Paulo: Companhia das Letras, 2010. 